\title{
Bioequivalence Assessment of Nabumetone Tablets in Healthy Korean Volunteers
}

\author{
In Chul ShIN* and Moon Hee ParK \\ Department of Pharmacology, College of Medicine, Hanyang University, 17 Haengdang-Dong, \\ Seongdong-Gu, Seoul 133-791, South Korea
}

(Received 12 June 2007; Accepted 26 June 2007)

\begin{abstract}
This study was performed to evaluate the bioequivalency between the Osmetone ${ }^{\mathrm{TM}}$ Tablet (Myeongmoon Pharm. Co., Ltd.) as a test formulation and the Relafen ${ }^{\mathrm{TM}}$ Tablet (Handok Pharm. Co., Ltd.) as a reference formulation. Twenty-four healthy male volunteers were administered the formulations by the randomized Latin square crossover design, and the plasma samples were determined by a high performance liquid chromatography (HPLC) with Ultra-Violet (UV) detector. $\mathrm{AUC}_{\mathrm{t}}, \mathrm{C}_{\max }$ and $\mathrm{T}_{\max }$ were obtained from the time-plasma concentration curves, and $\log$-transformed $\mathrm{AUC}_{\mathrm{t}}$ and $\mathrm{C}_{\max }$ and $\log$-untransformed $\mathrm{T}_{\max }$ values for two formulations were compared by statistical tests and analysis of variation. $\mathrm{AUC}_{\mathrm{t}}$ was determined to be $897.8 \pm 431.1 \mathrm{ug} . \mathrm{hr} / \mathrm{ml}$ for the reference formulation and $902.3 \pm 408.4 \mathrm{ug} . \mathrm{hr} / \mathrm{ml}$ for the test formulation. The mean values of $\mathrm{C}_{\max }$ for the reference and test formulations were $24.2 \pm 8.9$ and $24.0 \pm 9.5 \mathrm{ug} / \mathrm{ml}$, respectively. The $\mathrm{AUC}_{\mathrm{t}}$ and $\mathrm{C}_{\max }$ ratios of the reference Relafen ${ }^{\mathrm{TM}}$ Tablet to the test Osmetone ${ }^{\mathrm{TM}}$ Tablet were $+5.01 \%$ and $-0.83 \%$, respectively, showing that the mean differences were satisfied the acceptance criteria within $20 \%$. The results from analysis of variance for logtransformed $\mathrm{AUC}_{\mathrm{t}}$ and $\mathrm{C}_{\max }$ indicated that sequence effects between groups were not exerted and $90 \%$ confidence limits of the mean differences for $\mathrm{AUC}_{\mathrm{t}}$ and $\mathrm{C}_{\max }$ were located in ranges from $\log 0.80$ to $\log 1.25$, satisfying the acceptance criteria of the KFDA bioequivalence. The Osmetone ${ }^{\mathrm{TM}}$ Tablet as the test formulation was considered to be bioequivalant to the Relafen ${ }^{\mathrm{TM}}$ Tablet used as its reference formulation, based on $\mathrm{AUC}_{\mathrm{t}}$ and $\mathrm{C}_{\max }$ values.
\end{abstract}

Keywords $\square$ Nabumetone, Bioequivalence, Pharmacokinetics, HPLC

\section{INTRODUCTION}

Nabumetone is an antiinflammatory agents approved in 1991 for use in the United states. Clinical trials with nabumetone have indicated substanial efficacy in the treatment of rheumatoid arthritis and osteoarthritis, with a relatively low incidence of side effects and the dose typically is $1000 \mathrm{mg}$ given once daily (Friedel et al., 1993). Nabumetone is absorbed rapidly and is converted in the liver to one or more active metabolites, principally 6-methoxy-2-naphthylacetic acid, a potent inhibitor of cyclooxygenase. This metabolie is inactivated by demethylation in the liver, is then conjugated before excretion, and is eliminated with a half-life of about 24 hours (Friedel et al., 1993). Side effects of treatment with nabumetone include lower bowel complaints, skin rash, headache, dizziness, heartburn, tinnitus and pruritus. The incidence of

*Corresponding author

Tel: $+82-2-2220-0651, \quad$ Fax: $+82-2-2292-6686$

E-mail: icshin@hanyang.ac.kr gastrointestinal ulceration appears to be lower with nabumetone than with other Non-steroidal antiinflammatory drugs (Patrignani et al., 1994; Scott and Palmer, 2000).

Various kind of methods for determining nabumetone in human plasma have been reported (de Jager et al., 2000; Kobylinska et al., 2003; Mikami et al., 2000; Nobilis et al., 2004; Nobilis et al., 2003; Qin et al., 1999; Ray and Day, 1984).

In the current work a sensitive and simple HPLC method is described for the quantitation of nabumetone in human plasma and the bioequivalence study was performed by using the HPLC in healthy human volunteers after oral administration of nabumetone.

\section{MATERIALS AND METHODS}

Nabumetone tablets as the test product (Osmetone ${ }^{\mathrm{TM}}$ tablet, a $500 \mathrm{mg}$ tablet) was obtained from Myeongmoon Pharm. Co. (Seoul, Korea). The reference product (Relafen ${ }^{\mathrm{TM}}$ tablet, a 500 mg tablet) was obtained from Handok Pharm. Co. (Seoul, Korea). Ketoprofen used as the internal standard and citric acid 
were purchased from Sigma (St. Louis, MO, USA). 6-Methoxy-2-Naphthylacetic acid and 1-1-heptane sulfonic acid was obtained from Mp. Acetonitrile was purchased from Merck. All agents were of analytical grade.

After approval of pre-planed proposal by Korea Food and Drug Administration (KFDA), male volunteers who submitted the agreement to attend to this project were medically examined and 24 volunteers were selected by a medical doctor in Hanyang Medical Center (Seoul, Korea), based on clinical examination including seropathological (hemoglobin, hematocrit, WBC, platelet), serochemical (blood urea nitrogen, creatinine, total protein, albumin, SGOT, SGPT, total bilirubin, cholesterol, glucose fasting, akaline phosphatase) and urological (specific gravity, color, pH, sugar, alumin, bilirubin, RBC, WBC) data. An exclusion criterion for selecting volunteers includes talking frequently any medicine such as hypertensive agent and vitamins or nutrient aids. They were accommodated at the clinical pharmacokinetic room at the Hanyang Medical Center one day before blood collection. They were fasted for at least $12 \mathrm{hr}$ before administration of tablets. Lunch and dinner were allowed, respectively, 4 and $12 \mathrm{hr}$ after drug intake. Physical and biological examinations were carried out before and after completion of the study.

A 22-gauge i.v.. catheter on arm vein was established on the arm vein of each volunteer and $7 \mathrm{ml}$ of the blood were collected for blank. According to the prescription directed by a doctor, two tablets (a $500 \mathrm{mg}$ tablet, $1000 \mathrm{mg}$ nabumetone) were orally taken by each volunteer of the designated group at random design (12 volunteers a group) with $240 \mathrm{ml}$ of water. One group received test tablets, and the other reference tablets. These two groups were taken the formulation by the randonmized Latin square crossover design after a 2-week washing out period. Blood was collected into EDTA-treated tubes (Vacutainer) at 0, $0.33,0.66,1,2,4,6,8,10,12,24,48,72$ and $96 \mathrm{hr}$ after the oral administration. The time interval of blood sampling between volunteers was $2 \mathrm{~min}$ to consider blood collection time. Blood was centrifuged to obtain plasma. The plasma was stored at $-70^{\circ} \mathrm{C}$ until analyzed.

Nabumetone analysis was performed by HPLC with UV detector (Waters 486). Shiseido Nanospace SI-2 3023 autosampler was used and ds Chrom data module was supported by computer. The detector was set at $254 \mathrm{~nm}$. Symmetry $\mathrm{C}_{18}(4.6 \times$ $120 \mathrm{~mm}, 5 \mu \mathrm{m}$, Shiseido, Japan) column was used. The mobile phase for nabumetone analysis consists of acetonitrile and citric acid (20 mM), with 1-1-heptane sulfonic acid (550: $450: 0.3$ $<\mathrm{v} / \mathrm{v} / \mathrm{v}>$, $\mathrm{pH} 3.0$ ). The flow rate of the mobile phase was set to
$1.0 \mathrm{ml} / \mathrm{min}$. As the nabumetone is metabolized to 6-MNA (6methoxy-2-naphthylacetic acid), we measured the concentration of 6-MNA.

The stock solution of 6-MNA was prepared by dissolving it in acetonitrile as $1000 \mu \mathrm{g} / \mathrm{ml}$. Plasma sample were made. The concentrations of 6-MNA of plasma sample were 0.3, 1, 2.5, 5, 10,25 and $50 \mu \mathrm{g} / \mathrm{ml}$. Ketoprofen, internal standard, was dissolved in acetonitrile as $5 \mu \mathrm{g} / \mathrm{ml}$. To $180 \mathrm{ul}$ of the blank plasma, $20 \mathrm{ul}$ of the $0.3,1,2.5,5,10,25$ and $50 \mathrm{ug} / \mathrm{ml}$ of 6-MNA solution was added, respectively. $400 \mu 1$ Ketoprofen solution (5 ug/ $\mathrm{ml}$ ) was added. The tube was agitated for $1 \mathrm{~min}$ on a shaker. After centrifugation at $13000 \mathrm{rpm}$ and $4^{\circ} \mathrm{C}$ for $10 \mathrm{~min}$, the 100 ul supernatant was applied to the instrument. Calibration curves were made by ploting the concentrations of 6-MNA added at $\mathrm{x}$ axis and peak area ratios of the 6-MNA to internal standard at $\mathrm{y}$-axis. Intra- and inter-day precisions and accuracies were obtained from the five repeated experiment, respectively.

The frozen plasma samples were thawed at room temperature, vortex-mixed, and $200 \mu \mathrm{l}$ of the sample wa assed to the eppendorf tubes. Ketoprofen $(5 \mu \mathrm{g} / \mathrm{ml}$ in acetonitrile) was added to human plasma. The rest of the clean-up procedure was the same as described above. The nabumetone plasma concentrations in human volunteers were determined based on the calibration curves from peak area ratios of nabumetone to the internal standard.

Pharmacokinetic parameters were determined from the timeplasma concentrations of nabumetone. The highest concentration $\left(\mathrm{C}_{\mathrm{max}}\right)$ and the time to reach the highest concentration $\left(\mathrm{T}_{\max }\right)$ were read directly from time-plasma concentration curves of nabumetone. The area under the curve of timeplasma concentrations of nabumetone until the last sampling time $\left(\mathrm{AUC}_{0}\right.$ to last $)$ was determined by the equation of $\mathrm{AUC}_{0}$ to inf $=\mathrm{AUC}_{0 \text { to last }}+\mathrm{C}_{\text {last }} / \beta$, where $\beta$, is the slope of the terminal phase of the time-log plasma concentration curve and $\mathrm{C}_{\text {last }}$ is the concentration at the last sampling time (Shargel and $\mathrm{Yu}$, 1993).

Data are presented as mean \pm SD. K-BE test software (Seoul National University, Seoul, Korea) was used for data handling of bioavailability difference and $90 \%$ confidence limit for logtransformed $\mathrm{C}_{\max }$ and $\mathrm{AUC}_{\mathrm{t}}$ (Lee et al., 1993). In addition, ANOVA test was performed. The statistical analysis was performed for $\mathrm{C}_{\max }$ and $\mathrm{AUC}_{\mathrm{t}}$ after log-transformation: $90 \%$ confidence intervals and one-sided t-tests of Schuirmann were estimated and if $90 \%$ confidence limits of log-transformed $\mathrm{C}_{\max }$ and $\mathrm{AUC}_{\mathrm{t}}$. ranged from $\log 0.8$ to 1.25 at $\alpha=0.05$, two products are concluded to be bioequivalent (Schuirmann, 1987; 




Fig. 1. Chromatograms obtained by HPLC with a UV detector from human plasma blank with the internal standard (I.S.) and nabumetone. Ketoprofen was used as the internal standard. Nabumetone was eluted at $4.5 \mathrm{~min}$ and ketoprofen at $5.5 \mathrm{~min}$.

KFDA, 2002a; KFDA, 2002b).

\section{RESULTS AND DISCUSSION}

The plasma concentrations of nabumetone in healthy volunteers were determined and validated by HPLC with a UV detector. The HPLC chromatograms obtained from either its internal standard and nabumetone were showed in Fig. 1. Retention times of internal standard and nabumetone were about 5.5 and $4.5 \mathrm{~min}$, respectively and no interfering peaks were observed at these times, showing good separation between peaks. Total run time for determing one sample was within $10 \mathrm{~min}$. Precision and accuracy were presented in Table I. The lower limit of quantitation for nabumetone in human plasma was decided to be $0.3 \mathrm{ug} / \mathrm{ml}$, at which the within- and between day precision was less than $20 \%$ and $15 \%$, respectively, and $0.3 \mu \mathrm{g} / \mathrm{ml}$, at which the within- and between day accuracy was less than $5 \%$ and $15 \%$, respectively. The signal to noise ratios for nabumetone peaks were larger than 3 . The lin-



Fig. 2. The linearity of nabumetone calibration curve : $y($ ratio of peak area nabumetone to internal standard $)=0.0824 \mathrm{x}$ concentration of nabumetone $-0.006\left(\mathrm{r}^{2}=0.998\right)$.



Fig. 3. The time-plasma concentration curves of nabumetone in human volunteers after oral administration of two different products of nabumetone to healthy volunteers over $96 \mathrm{hr}$ at a dose of $1000 \mathrm{mg}$. Mean $( \pm \mathrm{SD})$ values of plasma nabumetone concentrations of 24 volunteers for test or reference formulations were represented.

earity of nabumetone calibration curve was good $\left(r^{2}=0.998\right)$ within the equation of $y$ (ratio of peak area nabumetone to internal standard $)=0.0824 \times$ concentration of nabumetone -0.006 at concentrations ranging from 0.3 to $50 \mathrm{ug} / \mathrm{ml}$. This data suggest that the method was suitable to determine the plasma concentrations of nabumetone and applicable to the pharmacokinetics and bioequivalence studies.

Table I. Precision and accuracy in within-a day and between-days for the determination of nabumetone in the human plasma

\begin{tabular}{lcccc}
\hline \multirow{2}{*}{ Concentrations $(\mu \mathrm{g} / \mathrm{ml})$ of nabumetone } & \multicolumn{2}{c}{ Precision $(\mathrm{CV} \%)$} & \multicolumn{2}{c}{ Accuracy $(\%)$} \\
\cline { 2 - 5 } & within-a day $(\mathrm{n}=5)$ & between-days $(\mathrm{n}=5)$ & within-a day $(\mathrm{n}=5)$ & between-days $(\mathrm{n}=5)$ \\
\hline 0.3 (lower limit of quantitation for nabumetone) & 2.4005 & 1.8488 & 102.78 & 114.49 \\
1 & 0.7036 & 6.9793 & 113.94 & 110.56 \\
2.5 & 0.4530 & 1.5210 & 102.42 & 103.09 \\
5 & 0.3221 & 4.6847 & 100.45 & 104.77 \\
10 & 0.1110 & 2.8029 & 95.89 & 97.48 \\
25 & 0.1615 & 0.6465 & 100.91 & 98.27 \\
50 & 0.1080 & 2.3561 & 99.96 & 100.55 \\
\hline
\end{tabular}


Table II. Bioavailability parameters obtained after oral administration of reference (Relafen ${ }^{\mathrm{TM}}$ Tablet) or test (Osmetone ${ }^{\mathrm{TM}}$ Tablet) drug containing $500 \mathrm{mg}$ nabumetone (as total $1000 \mathrm{mg}$ ) to human healthy volunteers

\begin{tabular}{|c|c|c|c|c|c|c|}
\hline \multirow{3}{*}{ Subject } & \multicolumn{6}{|c|}{ Bioavailability parameters } \\
\hline & \multicolumn{2}{|c|}{ AUC $(\mu \mathrm{g} . \mathrm{hr} / \mathrm{ml})$} & \multicolumn{2}{|c|}{$\mathrm{C}_{\max }$} & \multicolumn{2}{|c|}{$\mathrm{T}_{\max }$} \\
\hline & reference & test & reference & test & reference & test \\
\hline A1 & 438.6 & 506.8 & 13.8 & 14.7 & 4 & 8 \\
\hline A2 & 637.4 & 476.4 & 20.3 & 13.2 & 6 & 12 \\
\hline A3 & 695.0 & 1073.3 & 17.2 & 25.2 & 6 & 24 \\
\hline A4 & 1354.1 & 963.5 & 26.5 & 23.5 & 24 & 8 \\
\hline A5 & 1154.6 & 867.0 & 36.1 & 26.4 & 2 & 2 \\
\hline A6 & 1572.0 & 992.3 & 32.7 & 20.1 & 6 & 10 \\
\hline A7 & 687.1 & 538.9 & 22.7 & 20.1 & 8 & 8 \\
\hline A8 & 1282.6 & 855.6 & 28.1 & 27.3 & 8 & 8 \\
\hline A9 & 1234.1 & 569.2 & 29.7 & 14.1 & 6 & 2 \\
\hline A 10 & 443.3 & 1006.0 & 13.5 & 33.5 & 6 & 4 \\
\hline A11 & 1060.5 & 942.6 & 34.8 & 28.5 & 4 & 6 \\
\hline A 12 & 1036.6 & 1647.2 & 21.1 & 36.8 & 12 & 4 \\
\hline B1 & 941.4 & 706.9 & 31.1 & 23.8 & 4 & 6 \\
\hline B2 & 814.4 & 774.8 & 32.2 & 19.2 & 6 & 6 \\
\hline B3 & 1229.6 & 1302.2 & 31.1 & 30.6 & 4 & 6 \\
\hline B4 & 1993.3 & 1938.6 & 37.8 & 46.7 & 12 & 6 \\
\hline B5 & 877.3 & 879.8 & 28.3 & 23.8 & 6 & 6 \\
\hline B6 & 903.5 & 1415.8 & 21.3 & 35.0 & 8 & 24 \\
\hline B7 & 897.6 & 902.1 & 24.1 & 24.1 & 6.4 & 7 \\
\hline B8 & 951.7 & 1220.6 & 30.0 & 33.3 & 6 & 4 \\
\hline B9 & 575.7 & 600.6 & 20.9 & 18.7 & 4 & 4 \\
\hline B10 & 790.2 & 930.7 & 21.3 & 26.2 & 2 & 4 \\
\hline B11 & 459.7 & 822.6 & 16.1 & 19.7 & 4 & 4 \\
\hline B12 & 415.4 & 624.6 & 14.7 & 16.7 & 4 & 12 \\
\hline MEAN & 897.8 & 902.3 & 24.2 & 24.0 & 6.3 & 7.4 \\
\hline SD & 431.1 & 408.4 & 8.9 & 9.5 & 4.7 & 5.9 \\
\hline
\end{tabular}

Table III. Statistics for pharmacokinetic and bioequivalence parameters of nabumetone formulation

\begin{tabular}{lcc}
\hline & \multicolumn{2}{c}{ Parameters } \\
\cline { 2 - 3 } & $\mathrm{AUC}_{\mathrm{t}}$ & $\mathrm{C}_{\max }$ \\
\hline $90 \%$ confidence limit $^{\mathrm{a})}$ & $0.90 \leq \delta \geq 1.16$ & $0.86 \leq \delta \geq 1.13$
\end{tabular}

Log-transformed values of $\mathrm{AUC}_{\mathrm{t}}$ and $\mathrm{C}_{\mathrm{max}}$ were used for statistics of bioequivalence evaluation. ${ }^{\text {a) }} \alpha=0.05$.

From the time-plasma concentrations of nabumetone in healthy human after oral administration of two different products (Fig. 3), principal pharmacokinetic parameters were determined. The parameters for individual subjects are seen in Table II. The values of $\mathrm{AUC}_{\mathrm{t}}$ for the reference and test products were $897.8 \pm 431.1$ and $902.3 \pm 408.4 \mu \mathrm{g} . \mathrm{hr} / \mathrm{ml}$, respectively. The values of $\mathrm{C}_{\max }$ for the reference and test products were 24.2 \pm 8.9 and $24.0 \pm 9.5 \mu \mathrm{g} / \mathrm{ml}$, respectively. The values of $\mathrm{T}_{\max }$ for the reference and test products were $6.3 \pm 4.7$ and $7.40 \pm 5.9 \mathrm{hr}$, respectively.

The analysis of variance for $\mathrm{AUC}_{\mathrm{t}}$ and $\mathrm{C}_{\max }$ obtained from human volunteers was conducted and the results were presented in Table III. The mean differences of log-transformed $\mathrm{AUC}_{\mathrm{t}}$ and $\mathrm{C}_{\text {max }}$ at $90 \%$ confidence limit were determined to be $\log 0.90 \sim \log 1.16$ and $\log 0.86 \sim \log 1.13$, in which these two parameters satisfied the condition of the bioequivalence criteria that should be ranged from $\log 0.80 \sim \log 1.25$. Our data showed that most of these parameters satisfy the acceptance criteria of bioequivalence for two products.

The Osmetone ${ }^{\mathrm{TM}}$ tablet as a test formulation was considered to be bioequivalent to the Relafen ${ }^{\mathrm{TM}}$ tablet used as its reference formulation, based on pharmacokinetic data of nabumetone obtained from the time-plasma concentrations.

\section{REFERENCES}

de Jar, A. D., Hundt, H. K., Hundt, A. F., Swart, K. J., Knight, M. and Roberts, J. (2000). Extractionless determination of 6-methoxy-2-naphthylacetic acid, a major metabolite of nabumetone, in human plasma by high performance liquid chromatography. J. Chromatogr. B Biomed. Sci. Appl. 14;740(2), 247-251.

Friedel, H. A., Langtry, H. D. and Buckley, M. M. (1993). Nabumetone. A reappraisal of its pharmacology and therapeutic use in rheumatic diseases. Drugs 45, 131-156.

Kobylinska, K., Barlinska, M. and Kobylinska, M. (2003). Analysis of nabumetone in human plasma by HPLC. Application to single dose pharmacokinetic studies. J. Pharm. Biomed. Anal. 1;32(2), 323-328.

Lee, Y. J., Kim, Y. G., Lee, M. G., Chung, S. J., Lee, M. H. and Shim, C. K. (2000) Analysis of bioequivalence study using log-transformed model. Yakhakhoji 44, 308-314.

Mikami, E., Goto, T., Ohno, T., Matsumoto, H. and Nishida, M. (2000). Simultaneous analysis of naproxen, nabumetone and its major metabolite 6-methoxy-2-naphthylacetic acid in pharmaceuticals and human urine by high performance liquid chromatography. J. Pharm. Biomed. Anal. 23(5), 917-925.

Nobilis, M., Holcapek, M., Kolarova, L., Kopecky, J., Kunes, M., Svoboda, Z. and Kvetina, J. (2004). Identification and determination of phase II nabumetone metabolites by high performance liquid chromatography with photodiode array and mass spectrometric detection. J. Chromatogr. A. 26;1031, 229-236.

Nobilis, M., Kopecky, J., Kvetina, J., Svoboda, Z., Pour, M., Kunes, J., Holcapek, M. and Kolarova, L. (2003). Comparative biotransformation and disposition studies of nabumetone in humans and minipigs using high performance liquid chromatography with ultraviolet, fluorescence and mass spectrometric detection. J. Pharm. Biomed. Anal. 8;32, 641-656.

Patrignani, P., Panara, M. R., Greco, A., Fusco, O., Natoli, C., Lacobelli, S., Cipollone, F., Ganci, A., Creminon, C., and Maclouf, J. (1994). Biochemical and pharmacological characterization of the cyclooxygenase activity of human blood prostaglandin endoperoxide synthases. J. Pharmacol. Exp. Ther. 271, 1705-1712.

Qin, Y., Zou, Y., Liang, M., Huang, Y. and Yu, Q. (1999). Determination of 6-methoxy-2-naphthylacetic acid, a major metabolite of nabumetone, in human plasma by HPLC. Hua Xi Yi Ke 
DA Хие Хие Вао 30, 452-454

Ray, J. E. and Day, R. O. (1984). High performance liquid chromatographic determination of a new anti-inflammatory agent, nabumetone and its major metabolite in plasma using fluorimetric detection. J. Chromatogr. 7; 336, 234-238.

Schuirmann, D., J. (1987). A comparison of the two one-sided tests procedure and the power approach for assessing the equivalence of average $\mathrm{b}$ ioavailability. J. Pharmacokinet. Biopharm. 15, 657-680.

Scott, D. L. and Palmer, R., H. (2000). Safety and efficacy of nabumetone in osteoporosis: emphasis on gastrointestinal safety. Aliment. Pharmacol. Ther. 14, 443-452.

Shargel, L., and Yu, A., B., C. (1993). Chapter 10. Bioavailability and bioequivalence. In: Applied Biopharmaceutics and Pharmacokinetics, 3rd Ed., p.193, Appleton \& Lange, Norwalk, USA.

Korea Food and Drug Administration (KFDA; Nov 22, 2002a). Standard protocol for the criteria of bioequivalence test, KFDA Notification NO. 2002-60.

Korea Food and Drug Administration (KFDA; Nov 22, 2002b). Standard protocol for rgulations of bioequivalence test, KFDA Notification NO. 2002-61. 